\title{
Amenazador y amenazado: indetectabilidad, riesgo y sexualidad en la era del «tratamiento como prevención» del VIH-sida
}

\author{
Agostina Aixa Gagliolo \\ (iD) https://orcid.org/0000-0003-0985-8671 \\ Universidad de Buenos Aires \\ agostinagagliolo@gmail.com \\ Susana Margulies \\ (iD) https://orcid.org/0000-0001-5754-9529 \\ Universidad de Buenos Aires \\ sumargulies@gmail.com
}

\section{RESUMEN}

Este artículo recuper a la experiencia de personas con VIH residentes del Área Metropolitana de Buenos Aires, en torno del «tratamiento como prevención», núcleo central de las politicas globales contemporáneas de gobierno del VIH-sida. Se trata de una investigación etnográfica cuyo trabajo de campo (veinticuatro meses con una frecuencia de dos a tres visitas semanales de ocho a doce horas de duración cada una) se desarrolló entre 2016 y 2018. El corpus empírico consiste en trece entrevistas en profundidad y un extenso conjunto de registros de observación de interacciones cotidianas. Analizamos los modos en que indetectabilidad e intransmisibilidad del virus se entrelazan en la vida con la enfermedad. Mostramos que mientras las politicas presentan la relación indetectable-intransmisible como la clave para poner fin a la epidemia y a la vez como una poderosa herramienta para responder al estigma que rodea al VIH, estas relaciones se complejizan en la vida cotidiana de los afectados, dando lugar a procesos tensos y contradictorios entre percepción-interpretación-significación y prácticas. Entre estos procesos se destaca lo que llamamos una redirección del sentido del riesgo de enfermedad: desde la probabilidad de transmitir el virus 
a otros y otras hacia los otros y otras como fuente de trasmisión de nuevas condiciones de enfermedad.

Palabras clave: salud, etnografía, políticas globales, vida cotidiana, VIH, Buenos Aires, riesgo, tratamiento como prevención, indetectabilidad.

\title{
Threatening and threatened: undetectability, risk and sexuality in the «treatment as prevention» for HIV-Aids era
}

\author{
ABSTRACT
}

This article recovers the experience of people with HIV residing in the Metropolitan Area of the Buenos Aires Province, around "treatment as prevention» the central core of the HIV-Aids contemporary government policies. It's an ethnographic investigation with fieldwork (28-months) developed between 2016 and 2018. Our empirical corpus consists of 13 in-depth interviews and extensive records of everyday interaction observations. We analyze the ways in which the virus' undetectability and untransmittability engage into everyday life with HIV. We show that while policies present the undetectable-untransmittable relation as key to ending the epidemic and simultaneously as a powerful tool to respond to the stigma surrounding $H I V$, these relations become more complex in the everyday lives of those affected by it, giving rise to tense and contradictory processes between perception-interpretation-signification and practices. Amongst these processes what stands out is a redirection in the risk of disease: from the probability of transmitting the virus to others, towards others as a source of transmission for new diseases. Keywords: health, ethnography, global policies, everyday life, HIV, Buenos Aires, risk, treatment as prevention, undetectability. 


\section{INTRODUCCIÓN}

Era temprano por la mañana cuando llegué a la casa de Rafael, unos quince minutos antes de lo acordado. Me senté en la silla que me indicó mientras él vigilaba el agua para el mate, iniciando lo que sería una estadía de varias horas en este pequeño ambiente que oficia de casa y taller de costura. Demoramos casi media hora en comenzar la entrevista, que había sido pautada algunos días antes: las conversaciones con Rafael siempre son prolongadas. Este varon gay de 47 años autodenominado «talibán de las pastillas» (en referencia a su cumplimiento «religioso»—o quizás «fanático»— del tratamiento antirretroviral), repetía una y otra vez ese día «es un tema de tomar responsabilidad de lo que hiciste» mientras me contaba que había querido empezar su tratamiento antirretroviral en cuanto se enteró que tenía VIH: «[...] tenés que hacerlo si querés seguir y estar mejor, y tomar responsabilidades más que otra cosa».

La cuestión de la responsabilidad de los afectados ha estado presente en la historia de las respuestas al VIH desde sus inicios. Tempranamente, Frankenberg (1986) la caracterizó como una epidemia de significaciones asociada a categorías de estigmatización y prácticas de discriminación respecto de sujetos y grupos identificados con comportamientos sociales negativamente valorados y asimilados a fuentes de contagio de la enfermedad. Esta cuestión ha adquirido nuevos rumbos desde el surgimiento de la política global denominada «tratamiento como prevención», en la que la presión por sostener la indetectabilidad se asocia a la posibilidad de poner fin a la epidemia.

En el presente artículo exploramos las articulaciones problemáticas en la asociación indetectable-intransmisible, su relación con los procesos de fragilización asociados al VIH y la promesa de poner fin a la epidemia y reducir el estigma de las personas con VIH, colocando algunos interrogantes frente a las políticas globales contemporáneas de gobierno del VIH-sida. Recuperamos para ello la 
forma en que tales cuestiones fueron expresadas por un conjunto de personas con VIH que se atienden en un Programa Municipal de la Provincia de Buenos Aires, en el marco de una investigación etnográfica en curso cuyo trabajo de campo se desarrolló entre 2016 y 2018.

\section{EL «TRATAMIENTO COMO PREVENCIÓN»: UN NUEVO MODELO EN EL GOBIERNO DE LA EPIDEMIA DEL VIH-SIDA}

A partir del año 2011, las políticas internacionales de control de la epidemia del VIH-Sida se volcaron hacia la estrategia denominada «tratamiento como prevención ${ }^{1}$ (en adelante TasP - treatment as prevention, por sus siglas en inglés). Se partió de un conjunto de evidencias técnico-científicas que indicaban que el tratamiento antirretroviral de alta eficacia (en adelante TARGA - Terapia Antirretroviral de Gran Actividad) prolongado reducía la concentración del virus HIV-1 en los individuos afectados (Montaner y otros, 2006; Vernazza, Hirschel, Bernasconi y Flepp, 2008; Montaner, 2011) y que la reducción, medida por una carga viral plasmática menor de cincuenta copias de ARN viral por milímetro cúbico ${ }^{2}$, podía implicar la disminución del mismo en los fluidos corporales (semen, secreciones vaginales, sangre) (Montaner y otros, 2006). A la vez, niveles indetectables podían contribuir a eliminar la transmisión viral de un individuo a otro (UNAIDS, 2018a). Con esas evidencias, la estrategia de gobierno de la epidemia colocó como meta principal el control individual de la carga viral, sostenida a niveles indetectables por medio del uso continuado del TARGA y por este medio el control de la circulación del virus en el nivel comunitario - la

1 En una comunicación publicada por The Lancet en 2011, el médico Julio Montaner ilustra el cambio de paradigma en la estrategia de control de la epidemia señalando que «el tratamiento como prevención ha progresado de una hipótesis comprobable para transformarse en una prioridad de implementación urgente» (Montaner, 2011). La comunicación es posterior al consenso alcanzado durante el sexto Congreso de la International AIDS Society, la sociedad científica más prestigiosa del mundo y de la cual participan múltiples actores de relevancia en políticas vinculadas al VIH-sida. Allí, acordaron que la evidencia presentada sobre los beneficios del tratamiento antirretroviral en la reducción sustancial del riesgo de transmisión o adquisición del VIH era lo suficientemente sólida como para redireccionar las políticas en el ámbito global (IAS, 2011).

2 La carga viral indetectable se establece en función de la capacidad de medición de las tecnologías de laboratorio disponibles. Según una publicación de la DSETSHyT: “«Cuando se toma todos los días, el tratamiento antirretroviral evita que el virus se replique y disminuye su cantidad en sangre hasta niveles que no pueden ser detectados por análisis convencionales. Esto se llama "carga viral indetectable" [...]» (DSETSHyT, 2019). 
denominada carga viral comunitaria - , lo cual paulatinamente conduciría a la eliminación de la epidemia. Para alcanzar este propósito, se persigue una oferta ampliada de testeo, el tratamiento inmediato - lo antes posible - de las personas infectadas y la administración — de por vida— de medicamentos antirretrovirales (DSETSHyT, 2018).

Desde entonces, las metas y objetivos presentados por los grandes organismos internacionales para el control de la epidemia se han centrado en la ampliación del testeo y de la población bajo tratamiento, lineamientos que siguen instituciones nacionales e internacionales (ministerios de Salud, organizaciones de las Naciones Unidas, la Organización Mundial de la Salud, etcétera), gobiernos alrededor del mundo, organizaciones de personas afectadas, fundaciones públicas y privadas, y la industria farmacéutica y biotecnológica. En el año 2012 la Dirección de Sida, Enfermedades de Transmisión Sexual, Hepatitis y Tuberculosis Argentina (en adelante DSETSHyT) manifestó su adhesión a esta propuesta, incorporando sus lineamientos entre las metas locales. Para el período actual, entre 2015 y 2030, implica el plan Acción Acelerada (en inglés, Fast Track) desarrollado por ONUSIDA, cuyas metas se sintetizan en «90-90-90»: que para el año 2020 el 90\% de las personas que viven con el VIH conozcan su estado serológico positivo, que el $90 \%$ de esas personas estén bajo TARGA y que el 90\% de estos últimos tenga carga viral indetectable (UNAIDS, 2016).

Sin embargo, como señala la misma DSETSHyT en una publicación reciente, la existencia de una correlación entre la transmisión (por relaciones sexuales no protegidas o perinatal) del VIH y los niveles de carga viral plasmática no constituye una evidencia de descubrimiento reciente (DSETSHyT, 2019). Los primeros estudios epidemiológicos que establecieron dicha correlación datan de 1997, cuando se estableció que la presencia de altos valores de carga viral en una mujer embarazada se asociaban a mayores probabilidades de transmisión del VIH por vía perinatal, sugiriendo que el uso de terapias combinadas durante el embarazo podría reducir las tasas de transmisión (García, 2014). Esta correlación «indetectable=intransmisible» (en adelante I=I) (UNAIDS, 2018a) se amplifica y resignifica en el contexto de los nuevos desarrollos biotecnológicos y farmacológicos que han contribuido a transformar la historia y el carácter del VIH-sida de una enfermedad mortal a una condición de larga duración.

Las políticas asociadas al TasP reconfiguran de este modo el uso del TARGA, que ya no solo constituye una herramienta clínico-terapéutica para detener la progresión viral contribuyendo a la supervivencia individual, sino que pasa a ser —además - la tecnología clave para la protección colectiva frente al VIH 


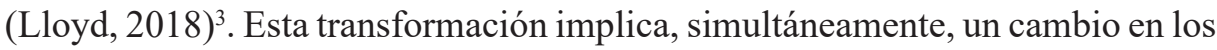
modos en que se configuró históricamente la respuesta internacional al sida: de un modelo sanitario basado en políticas y tecnologías de promoción y educación sanitaria con participación de los afectados, o de acciones de control selectivo orientadas a individuos en riesgo diferencial de contraer la enfermedad, se pasa a un modelo focalizado en el control viral (Margulies, 2015). Esta cuestión ha sido analizada por algunas autoras señalando que este paradigma de gobierno de la epidemia reduce a los sujetos y su experiencia a poblaciones epidemiológicamente homogéneas, cuya carga viral agregada debe ser reducida (Margulies, 2015; Cormier McSwiggin, 2017).

En los últimos años, la correlación I=I ha sido presentada además en publicaciones de organismos internaciones y nacionales como una herramienta poderosa y efectiva para responder al estigma de las personas con VIH (UNAIDS, 2018a; DSETSHyT, 2019). Lo mismo se lee en una editorial de la revista The Lancet $H I V^{4}$ en 2017. En este sentido, se señala:

Para muchas personas viviendo con VIH, la noticia de que ya no transmiten el VIH sexualmente transforma sus vidas. Además de poder elegir mantener relaciones sexuales sin preservativo, muchas personas viviendo con VIH viralmente suprimidas se sienten liberadas del estigma asociado a vivir con el virus. El conocimiento de que ya no transmiten el VIH sexualmente puede proveer a las personas viviendo con VIH del fuerte sentido de ser agentes de prevención en la búsqueda de relaciones nuevas o existentes (UNAIDS, 2018a, p. 2 traducción y resaltados propios).

En el ámbito local, la DSETSHyT dice al respecto:

I=I es una poderosa herramienta para la prevención del VIH y un mensaje que intenta desterrar la idea de la persona con VIH como «fuente de contagio», «responsable de la epidemia»y «riesgo para el entorno». I=I es además una herramienta sólida para responder al estigma institucional que ocurre en centros asistenciales de salud, lugares de trabajo y la sociedad en general, al estigma interpersonal y al estigma internalizado, que incluye las creencias

3 Esto se expresa con claridad en lo enunciado por la DSETSHyT: «El TasP se refiere al uso universal de tratamiento antirretroviral no solo para mejorar la salud y calidad de vida de las PcVIH sino también como una estrategia para reducir la transmisión y la incidencia del VIH a escala poblacional» (DSETSHyT, 2019).

4 The Lancet es una revista médica de origen británico y de gran prestigio en el mundo académico. Entre sus ediciones especializadas se destaca The Lancet HIV. Para más detalle ver: https://www.thelancet.com/ 
negativas sobre el VIH que tienen las personas que viven con el virus (DSETSHyT, 2019, p. 4 resaltado propio).

\section{LOS ESTUDIOS SOCIOANTROPOLÓGICOS SOBRE POLÍTICAS GLOBALES Y VIH-SIDA}

Las políticas globales de control de la epidemia del VIH-sida han sido ampliamente analizadas desde la perspectiva socioantropológica (Fassin, 2007; Lloyd, 2018; Manderson \& Smith-Morris, 2010; Moyer, 2015; Petryna, Lakoff y Kleinman, 2006; Sangaramoorthy, 2012; Sullivan, 2012). Para este artículo, recuperamos en particular un conjunto de trabajos de matriz foucaultiana que han abordado la capacidad productora de sujetos de los discursos y tecnologías biomédicas (en tanto regímenes disciplinarios) y cómo la racionalidad biomédica interviene en nuevas lógicas de gobierno (Novas y Rose, 2000; Persson, Race y Wakeford, 2003; Rabinow, 2008; Rose, 2001; Rose y Novas, 2008).

En esta línea de trabajos se ha señalado la centralidad de los fenómenos somáticos para la vida social, atendiendo a procesos en los que sujetos modelan la relación con su cuerpo y el mundo a partir de condiciones biológicas o fisiológicas (Biehl y Moran-Thomas, 2009). Así, se ha recuperado la centralidad que las instituciones, los mercados, las biotecnologías y las intervenciones médico-técnicas tienen en la constitución de novedosas formas de subjetividad y ciudadanía (Ecks, 2005; Nguyen, 2004; Petryna, 2004; Reynolds Whyte, 2013). En esta línea, se ha planteado que los procesos de responsabilización asociados a la medicina del riesgo (Aronowitz, 2015) generan, a su vez, complejas reconfiguraciones subjetivas (Dumit, 2012 en Rohden, 2018) que implican un doble proceso por medio del cual el hecho o artefacto médico es incorporado a la vida de la persona y simultáneamente la persona pasa a comprenderse a sí misma en cuanto objeto.

Por otra parte, se destacan los aportes de Biehl, quien ha abordado lo que denominó la lógica de gobierno farmacológico del sida y la centralidad del abordaje técnico de problemáticas de salud poblacionales y la distribución de biotecnología en el plano global, ajeno a los contextos y las infraestructuras de salud disponibles ( Biehl, 2007, 2008b, 2008 ; Petryna y otros, 2006). Asimismo, diversas autoras han señalado que la «agenda global para poner fin al sida» gira en torno a un despliegue sistemático del tratamiento antirretroviral en escenarios muy diversos, partiendo de la noción de que las tecnologías biomédicas tienen efectos uniformes y predecibles independientemente de los contextos y las poblaciones en los que 
son implementadas, y que es tal abordaje homogeneizador el que dotaría a estas tecnologías de una supuesta portabilidad y efectividad (Persson y otros, 2019). Estos últimos han analizado en particular los flujos globales de biotecnología asociados al VIH-sida, observando sus efectos productivos (en inglés, constitutive effects) en los encuentros con la vida en el nivel local.

Se ha planteado en este marco que las biotecnologías coexisten y se articulan en la conformación de realidades sociales, en el entrelazamiento entre intereses locales, globales, condiciones políticas y económicas, marcos regulatorios, relaciones de género, normas sociales, sistemas de salud y prácticas culturales. En este marco, Biehl ha enfatizado en la importancia del acercamiento etnográfico a las micropolíticas de supervivencia de las personas con VIH con el propósito de mostrar cómo subjetividades y formas de ciudadanía se configuran en la intersección entre políticas, biotecnologías, servicios de salud y vida cotidiana (Biehl, 2007).

\section{METODOLOGÍA}

Este artículo se propone abrir algunos interrogantes sobre estas políticas del sida colocando la mirada en la vida cotidiana de las personas afectadas por el VIH que se encuentran bajo tratamiento. Nuestro corpus empírico consiste en un conjunto de entrevistas ${ }^{5}$ (trece) y registros de observación de interacciones cotidianas con personas con VIH que acuden a un Programa Municipal de Prevención y Asistencia del VIH-sida y Adicciones, todos residentes del Área Metropolitana de Buenos Aires. Las entrevistas y registros fueron realizados en el marco de una investigación etnográfica, cuyo trabajo de campo se extendió entre 2016 y 2018.

El programa en el cual se desarrolla esta etnografía fue creado en 1992, muy tempranamente en la historia de las respuestas a la epidemia en Argentina, antes incluso de que existiera la Dirección Nacional de VIH-sida e ITS (ahora DSETSHyT). Desde sus orígenes se encuentra emplazado en un Centro de Atención Primaria (en adelante CAP) ubicado en el primer cordón poblacional conurbano de la provincia de Buenos Aires. A este lugar acuden personas que recibieron sus diagnósticos o tratamientos de VIH a finales de la década de 1980 y comienzos de la de 1990. En la actualidad cuentan con un promedio de noventa pacientes

Las personas que fueron entrevistadas prestaron su consentimiento informado de forma escrita a la investigadora. Asimismo, esta investigación fue aprobada por el Comité de Ética de la Facultad de Filosofía y Letras de la Universidad de Buenos Aires. 
con VIH bajo seguimiento ${ }^{6}$. Como la mayoría de estas personas acude cada dos meses, el promedio de consulta mensual (calculado sobre el registro de dispensa de medicación) es de 45 . Entre los pacientes activos, un $63 \%$ son varones cuyas edades se distribuyen en: $9 \%$ entre 20 y 26 años; $22 \%$ entre 27 y 38 años; $52 \%$ entre 39 y 54 años y $17 \%$ entre 55 y 70 años. El restante $37 \%$ está compuesto por mujeres cuya distribución etaria es de: $28 \%$ entre 27 y 38 años (no hay mujeres menores a 27 años bajo tratamiento); $51 \%$ entre 39 y 54 años y $21 \%$ entre 55 y 70 años.

El trabajo de campo comprendió un período de veinticuatro meses distribuidos entre 2016 y 2018, desarrollado en tres etapas (agosto-diciembre 2016, enero-diciembre 2017 y febrero-agosto 2018), con visitas periódicas al servicio en los días y horarios en los que se brinda atención a personas con VIH (esta frecuencia varía entre dos y tres visitas semanales, cada una de ocho a doce horas de duración), e incluyó la observación de actividades de asistencia y gestión en las oficinas del programa municipal, múltiples y prolongadas conversaciones informales con profesionales y pacientes en diferentes ámbitos del CAP (sala de espera, pasillos, oficinas, consultorios), otros centros del municipio y actividades al aire libre, la participación en las reuniones mensuales de un grupo de pares desarrollado por una organización de personas con $\mathrm{VIH}$, la realización de entrevistas a profesionales dentro del espacio asistencial y entrevistas en profundidad a trece pacientes fuera de él.

Las entrevistas fueron grabadas y luego entextualizadas ${ }^{7}$ y anonimizadas ${ }^{8}$. De las trece personas entrevistadas, seis eran varones autodenominados como gais, cuatro eran varones heterosexuales o con parejas heterosexuales y tres eran mujeres heterosexuales o con parejas heterosexuales ${ }^{9}$. Sus edades oscilan entre

6 Además de la atención médica, el programa realiza atención psicológica, orientación en demandas sociales, asesoramiento en el testeo y realización de testeo rápido para VIH. Considerando todos estos servicios, el número de consultas se estima en un promedio de 150 por mes.

7 Bauman y Briggs (1990) proponen el término entextualización para referir al proceso «de hacer extraíble el discurso, de convertir un fragmento de producción lingüística en una unidad —un texto- que puede separarse de su marco interaccional». En este sentido, dicen los autores, «un texto es discurso vuelto descontextualizable» (p. 72, traducción nuestra). Según Oxman (1998) la entrevista de investigación produce una forma específica de entextualización que configura un material extraído del evento comunicativo apto para su recontextualización académica.

8 Todos los nombres originales han sido reemplazados por otros ficticios en este escrito, con el fin de preservar el anonimato.

9 Hacemos referecia a la orientación sexual de las personas aquí entrevistadas por tratarse ella de un elemento que ha sido señalado como significativo en torno a la definición de mayor o menor riesgo de exposición frente al VIH. 
27 y 66 años, con predominancia de las personas entre 39 y 54 años. Todas estas personas se encontraban realizando tratamiento antirretroviral. En este artículo recuperamos con mayor detalle los aportes de varones - y particularmente varones autodenominados gais - por ser con quienes más detallada y prolongadamente conversamos acerca de sus prácticas sexuales y las preocupaciones con respecto al VIH en ese marco. Asimismo, como se señala más arriba, los varones representan alrededor del $63 \%$ de los pacientes activos.

Al preguntarnos sobre la cuestión de la indetectabilidad, partimos de considerar que es producida, o en términos de Mol y Law (2004) actuada, en la vida cotidiana de las personas con VIH. Es decir, producir la indetectabilidad implica un conjunto de acciones cotidianas que se orientan hacia ese fin. Comprendemos las indetectabilidades (y las enfermedades en sí) como co-constituidas en este entramado de relaciones que se dan en el marco de las acciones cotidianas orientadas a actuar sobre las vicisitudes de la vida, siempre situadas en un campo de posibilidades que los actores habitan (Alves, 2014). Particularmente, en el caso del VIH, ser indetectable implica la toma cotidiana, regular y sostenida en el tiempo de la medicación antirretroviral — lo que es médicamente denominado como adherencia al TARGA - y el control de los niveles de virus en sangre a través del monitoreo de indicadores químicos de laboratorio (la carga viral y el CD4). Entre las personas que forman parte de este estudio existen diferencias en cuanto a sus tratamientos: mientras que algunos atravesaron momentos de tomas diarias de muchos comprimidos, incluyendo esquemas de monoterapia o biterapia (antes de que existiera amplia disponibilidad del TARGA ${ }^{10}$ en Argentina), otros comenzaron cuando la provisión de TARGA no se encontraba regularizada en el país y un tercer grupo inició sus terapias cuando comenzó a ampliarse la disponibilidad de tratamientos co-formulados o simplificados ${ }^{11}$ con una reducción significativa de los efectos adversos, de las tomas diarias de comprimidos y de las restricciones dietarias. En este punto, es relevante señalar que Argentina cuenta

10 Existe consenso generalizado en establecer el inicio del TARGA a partir de la creación del fármaco Saquinavir en 1995 y la posterior aparición de los inhibidores de la transcriptasa inversa no nucleósidos (el primero de ellos la Nevirapina). La combinación de estas nuevas drogas con el ya existente AZT, Zidovudina (inhibidor nucleósido de la trascriptasa inversa) constituyen el TARGA.

11 En Argentina, el Atripla fue el primer comprimido 3-en-1 (de una toma diaria) incorporado al Vademecum del Ministerio de Salud de la Nación. Comenzó a estar disponible para todos los pacientes con VIH entre el año 2013 y 2014. Antes de este, ya existían otras co-formulaciones que reducían la toma a dos o tres veces por día. 
con provisión universal y gratuita de tratamiento antirretroviral ${ }^{12} \mathrm{y}$ de estudios de laboratorio, estipulada en la normativa nacional (Ley Nacional de Sida 23.789 y sus decretos reglamentarios, 1990). En el caso de quienes acuden al programa municipal aquí señalado, su atención comprende también la provisión de medicamentos antirretrovirales de modo mensual, bimestral o trimestral (periodicidad que establece la médica infectóloga) y la realización bianual (o trianual) de estudios de laboratorio. Cabe señalar que en 2019 se registraron frecuentes casos de faltantes de provisión de reactivos para estos estudios.

A partir del análisis del registro de las interacciones mencionadas (incluyendo entrevistas y conversaciones informales) recuperamos los modos en que los sujetos articulan sentidos, significados y prácticas $^{13}$ colocando en diálogo discursos y tecnologías biomédicos (incluyendo diversas nociones de riesgo, interacciones con tratamientos antirretrovirales, mediciones de laboratorio, etcétera), prácticas de cuidado, transformaciones y sensaciones corporales, nociones de sí y emociones (miedos, preocupaciones, incertidumbres, sufrimientos, deseos). Situados en el contexto del TasP, estos relatos remiten a la cuestión de la indetectabilidad y su asociación a la intrasmisibilidad como condición y garantía para poner fin a la epidemia.

12 El sistema de salud en Argentina es el resultado de la coexistencia de tres subsistemas: privado (compuesto por empresas que brindan cobertura a quienes realicen el pago voluntario), de obras sociales (trabajadores en relación de dependencia y es financiado por las contribuciones de empleadores, trabajadores y del Estado) y público (financiado con recursos provenientes del Estado, de cobertura universal). En el caso del VIH, aquellas personas que se encuentren bajo los subsistemas privado o de obras sociales no reciben cobertura por el sistema público. Todos los subsectores se encuentran bajo la obligación de proveer las prestaciones correspondientes a sus beneficiarios (atención, medicamentos, estudios de laboratorios, internaciones en caso de ser necesarias, etcétera). Para información sobre la composición del sistema de salud en Argentina véase Ministerio de Salud de la Nación. 2010. Políticas de Salud: Programa Médicos Comunitarios. Módulo 5. Programa Médicos Comunitarios. Buenos Aires: Ministerio de Salud de la Nación.

13 Nuestro punto de partida es que las enfermedades son simultáneamente materiales y significativas (Good, 1993). En este sentido, múltiples autores han señalado que la separación entre realidad y la representación sobre la realidad pierde sentido (Carrithers, Candea, Sykes, González-Abrisketa y Carro-Ripalda, 2016; Holbraad, 2014; Holbraad y Venkatesan, 2010; Mol, 2002, entre otros). Consideramos en este marco que las actividades como observar o representar y también relatar o narrar son formas de acción, maneras de producir realidades (Almeida Souza, 2012). 
«ES UN TEMA DE TOMAR RESPONSABILIDAD POR LO QUE HICISTE» - LA INDETECTABILIDAD COMO HERRAMIENTA PARA PONER FIN A LA EPIDEMIA

A partir de lo descrito hasta aquí, es posible plantear que el TasP en tanto política global de respuesta al sida tiende a colocar en el accionar individual de los sujetos afectados la posibilidad - y la responsabilidad - del control y erradicación de la epidemia. Esto puede inferirse a partir de aquella fórmula según la cual la sumatoria de sujetos con cargas virales indetectables obtenidas por medio de la adherencia casi perfecta al tratamiento antirretroviral podría conducir a la paulatina eliminación de la transmisión viral en la población, poniendo fin al VIH-sida. Sobre esta cuestión resuena la afirmación de Rafael señalada al comienzo de este artículo: «[...] Es un tema de tomar responsabilidad por lo que hiciste...».

Históricamente, las personas afectadas por el VIH/sida fueron presentadas como peligrosas o amenazantes. Autoras como Pierret han señalado que el peso de los discursos sociales y las representaciones sociales y mediáticas en torno al VIH - particularmente aquellas vinculadas con la muerte, el temor del otro y el carácter potencialmente peligroso de la persona infectada - han sido claves en la constitución del estigma asociado al VIH (Pierret, 2000). Tales representaciones han tendido a adjudicar el riesgo de contraer la enfermedad y la responsabilidad por su expansión a un otro amenazador (Watney 1989, en Grimberg, 2002b) fuertemente asociado a nociones como las de suciedad, contaminación y fuente de infección (Crawford, 1996). Tales sujetos han sido también vinculados con prácticas socialmente sancionadas como promiscuas, transgresoras o desviadas, particularmente en la arena de las relaciones y prácticas sexuales (Alonzo y Reynolds, 1995; Grimberg, 2000). Se ha señalado en este sentido cómo la identificación de sujetos y conjuntos sociales en grupos de riesgo - sobre la base de la consideración de elementos frecuentemente superficiales y divorciados del contexto social y cultural (Frankenberg, 1994) genera la base para un desplazamiento de significación de grupos de riesgo a grupos culpables (Merkier y Margulies, 1998).

El lenguaje del riesgo ha sido central en la construcción médica y social de la causa del sida, estableciendo un puente entre lo individual y lo colectivo en la concepción atomista dominante de la enfermedad (Margulies, 2015). De este modo, el riesgo pasa de ser una probabilidad estadística a convertirse en la posibilidad individual de desarrollar la enfermedad. Esta individualizaciónresponsabilización del riesgo en el caso del VIH-sida presenta dos elementos 
centrales: la prevención de la trasmisión viral y el cumplimiento o adherencia de los tratamientos antirretrovirales, ambos acompañados del imperativo moral de cuidar de sí y cuidar de otros. Castro y Farmer (2003) han analizado cómo la estigmatización vinculada al VIH/sida que arrastra la lógica de la culpabilización de los afectados sitúa la causa de la enfermedad en las propias personas, despojándola de su carácter social, incrementando el sufrimiento de los sujetos afectados. Cormier Mcswiggin (2017), en su estudio con población haitiana con VIH residente en Miami, ha analizado los efectos estigmatizantes de la detectabilidad (en oposición a la indetectabilidad) en la era del TasP, atendiendo a los modos en que detectablidad e indetectabilidad son constituidas como elecciones que separan a los sujetos entre responsables e irresponsables.

\section{«CUIDARSE» O NO: ENTRE LA CERTEZA Y LA INCERTIDUMBRE ALREDEDOR DEL I=I}

Cirilo, oriundo de La Rioja, tenía 29 años y hacía cuatro que vivía en Buenos Aires, donde se trasladó en búsqueda de una mejor atención, y también de oportunidades laborales que no encontraba en su ciudad de origen. Este varón de piel morena, alto y delgado que frecuentemente tenía el pelo teñido de algún color estridente, residía con su pareja en un partido del tercer cordón del conurbano bonaerense, desde donde viajaba unas dos horas para atenderse en el centro de salud. Recibió su diagnóstico de VIH en 2011, unos días después de haberse realizado un test que le ofrecieron cuando fue a completar su Libreta Sanitaria, e inmediatamente inició su tratamiento ${ }^{14}$ antirretroviral, que había continuado sin interrupciones, pero sí con algunos cambios en sus esquemas. Tomaba sus medicamentos tres veces por día. Cirilo es gay y se reunía con un grupo de jóvenes LGBT con quienes compartía sus dudas sobre el VIH en «mateadas por la diversidad» $»^{15}$. Es allí donde encontró las primeras explicaciones que vinculaban el estar indetectable

14 Las indicaciones sobre inicios de tratamiento fueron variando a lo largo de los años tanto a nivel internacional como local. En 2013 la «Guía para el manejo de los pacientes adultos con infección por VIH» (DSETSHyT, 2013) indicaba iniciar tratamiento — si se tratase de casos asintomáticos - solo en pacientes cuyo recuento de CD4 fuera inferior a 500, mientras que en la actualidad se considera que todos los pacientes diagnosticados deben iniciar tratamiento, independientemente de su recuento de CD4 (DSETSHyT, 2018).

15 Las «mateadas por la diversidad» fueron descritas por Cirilo como encuentros de jóvenes LGBTque se desarrollan en diferentes plazas de la provincia de Buenos Aires. En ellos la propuesta es compartir un mate, algo para comer, y conversar sobre diferentes cuestiones vinculadas con sus experiencias de vida. 
con lo que él llamaba «no contagiar». En el extracto que sigue, el «contagio» para referir a la trasmisión viral y el «cuidarse» son nociones centrales en la expresión de la responsabilidad moral asociada al padecer esta enfermedad:

[Al estar indetectable] me siento más tranquilo, porque lo que me dan a entender otras personas [es que] cuando estás indetectable [...] no contagiás en tanta, en tanta cantidad, ni tanta dimensión. Por eso algunas personas, no te digo que yo lo hago ni tampoco muchos, pero a unas ciertas personas hacen eso, en tener relaciones sin cuidarse, o parejas mutuamente que tienen el mismo el tema y no les importa nada y tienen relaciones sin cuidarse, porque supuestamente están indetectables y todo el tema y bueno y están en la jugada esa de no cuidarse. Porque según lo que los médicos a esas personas le dan a entender que no contagian nada, o contagian en muy poca cantidad. Supuestamente el virus es muy débil, es lo que ellos me explican, lo que ellos me dicen a mí (entrevista Cirilo 19/02/018 - resaltado propio).

Cirilo dice estar más tranquilo por «estar indetectable», pero simultáneamente coloca algunos reparos y manifiesta preocupación. Aunque el virus sea ahora «débil», mantener relaciones sexuales «sin cuidarse» (entendiendo aquí esta expresión como sinónimo de no usar preservativo) continúa siendo un acto de exposición frente a la posibilidad - aunque sea pequeña - de contagiar el VIH. Así, Cirilo duda sobre las posibilidades concretas de no transmitir el virus cuando se encuentra indetectable, al punto tal que señala haberle preguntado por la «verdad» a su médica y haber obtenido una respuesta completamente diferente: «Yo le pregunté a la doctora si era verdad o mentira, la doctora me dijo que nada que ver lo que ellos te dicen, o lo que los médicos les dicen a ellos, porque estás indetectable, pero igual contagiás. Pero bueno» (entrevista Cirilo 19/02/2018 resaltado propio).

Cirilo expresa incertidumbre frente a la posibilidad de que estar indetectable implique no trasmitir el virus y es con esta incertidumbre que transita su vida siendo indetectable.

Ernesto, un varón gay de 66 años, militante, establecía con precisión biomédica la correlación $\mathrm{I}=\mathrm{I}$ aquella tarde que lo conocí en el grupo de pares que sesionaba una vez por mes en el Programa Municipal ${ }^{16}$ y al que él había sido

16 El así denominado «grupo entre pares» es un espacio organizado por una asociación de personas viviendo con VIH del conurbano bonaerense. En el marco del Programa Municipal, sus reuniones se efectuaban de manera mensual, coordinadas por dos pacientes de allí. En general quienes participaban eran otros pacientes, aunque ocasionalmente acudían personas invitadas de la misma o de otras organizaciones de personas con VIH, o de otros grupos que 
invitado en calidad de activista por su participación en una organización de personas con VIH. Este hombre alto, blanco, de ojos celeste claros, espalda ancha y levemente encorvada, se presentó como «completamente fuera del armario» en todos los aspectos de su vida. Su diagnóstico lo recibió en 1989, luego de que lo recibiera su expareja, quien murió seis meses después. Solo inició su tratamiento antirretroviral luego de muchas «negociaciones» con su médico, en 2013. No recordaba qué medicamentos tomaba, pero sí que lo hacía dos veces por día. Ernesto nunca había abandonado su tratamiento, pero evitaba tomar sus pastillas en determinados momentos y situaciones, como cuando tenía un resfrío y no quería «saturar» su cuerpo. Esa tarde en el grupo de pares, con su voz profunda y grave, casi dirigiéndose a un auditorio, dijo a los presentes:

«[...] Ahora, estando indetectable, no hay transmisión. Huésped tiene 140000 casos que comprueban eso», aunque inmediatamente aclaró que igual usaba preservativo en sus relaciones sexuales «porque podés no transmitir VIH, pero sí cualquier otra enfermedad». Rafael [quien también participaba del grupo] le contestó: «Claro, el problema es que ahora los jóvenes tampoco quieren usar preservativo», comentario que dio origen a una conversación sobre los saunas y los cines (espacios donde algunos varones gais mantienen relaciones sexuales). Ernesto dijo: «Ahí en los saunas no se usa preservativo, el montar a pelo - el barebacking ${ }^{17}$ — es un problema dentro de la comunidad gay» (registro de campo nº45 05/09/2017).

Ernesto es el único de las personas que entrevisté que reprodujo con tanta precisión el discurso de las políticas globales del sida. Fue el único que habló de la intransmisibilidad asociada a la carga viral indetectable en términos de un hecho científico comprobado, apelando a una investigación desarrollada por la prestigiosa fundación Huésped ${ }^{18}$. Más aun, su ubicación de la importancia de este hecho en la comunidad gay otorgó un sentido comunitario similar al propuesto por Montaner (2006), el reconocido ideólogo de esta política. Sin embargo, es

frecuentaban las personas que componían este espacio (Narcóticos Anónimos, Alcohólicos Anónimos, etcétera).

17 El barebacking, generalmente traducido como «montar a pelo», es un término originado de la comunidad gay que se utiliza para designar las prácticas sexuales sin uso de preservativo. Fundamentalmente se asocia al sexo anal entre varones cis, pero también puede ser utilizado para designar cualquier práctica sexual que incluya la penetración y se realice sin preservativo.

18 La fundación Huésped es una organización no gubernamental argentina con alcance regional creada en 1989, que trabaja temáticas vinculadas con el VIH-sida. Entre sus actuaciones se destacan la atención hospitalaria y la realización de ensayos clínicos en convenio con organismos internacionales y locales https://www.huesped.org.ar/ 
significativo destacar que él mismo señaló la importancia del uso de preservativo en las relaciones sexuales. En su relato pareciera despejarse la peligrosidad asociada al VIH, pero abriendo a la consideración de «otras enfermedades» que aparecen como amenazadoras en el contexto de las relaciones sexuales no protegidas (por preservativo).

En otra de nuestras conversaciones, esta vez en su departamento de la Capital Federal, Ernesto dio contenidos y sentidos diferentes a la indetectabilidad. Ese día, entre mate y mate, Ernesto refirió sobre sus relaciones sexuales:

A: ¿Y en general a quién le contás o no le contás?

E: [...] En general yo lo hablo, después si tengo algún compañero sexual transitorio, bueno, tomo las precauciones del caso pero no, no me interesa [decir que tiene $\mathrm{VIH}$ ], salvo que se dé la charla, porque en general estoy abierto a hablar del tema (entrevista Ernesto 26/09/2017 - resaltado propio)-

Así, en sus respuestas pudimos registrar dos formas de referir la indetectabilidad. Una está vinculada con el espacio público, en el que claramente establece la correlación $\mathrm{I}=\mathrm{I}$ al tiempo que coloca la preocupación sobre las prácticas sexuales sin preservativo en el marco de la comunidad gay (o de las prácticas específicas de los varones gais y sus ámbitos de sociabilidad). Otra, en la que remite a su vida cotidiana, en la que indetectabilidad no se asocia directamente a intransmisibilidad sino a una condición de las relaciones sexuales con VIH, que exige ser explicitada («hablado») o al menos que requiere tomar recaudos («precauciones del caso»).

\section{LAS RELACIONES SEXUALES COMO LOCUS DEL RIESGO EN LA INDETECTABILIDAD}

Hasta aquí nos encontramos primero con Cirilo, quien expresa dudas sobre la «verdad» de la relación I=I, y luego con Ernesto, quien, aunque la sostiene como cierta, mantiene un sentido de peligrosidad de la vida sexual vinculado con «otras enfermedades».

Con Leandro, las conversaciones comenzaron siempre rondando las múltiples afecciones que lo aquejaban desde semanas antes de recibir su diagnóstico en 2013, afecciones que lo habían llevado a más de una internación. Leandro es varón y tiene una pareja heterosexual. Cuando lo conocí tenía menos de cuarenta años, pero su aspecto era de alguien mucho mayor. Su semblante, con ojeras pronunciadas y la espalda encorvada, evoca el sufrimiento provocado por las enfermedades 
recurrentes que no dejaban de acecharlo desde el año 2013. Este varón, que supo ser físico-culturista, ahora es extremadamente delgado. Su salud había empeorado mucho en los últimos años, al punto de no poder caminar sin agitarse, haciéndole imposible sostener un trabajo. Inició su tratamiento antirretroviral ni bien fue diagnosticado, y no lo había abandonado nunca voluntariamente, aunque tuvo que suspenderlo en más de una ocasión por causa de otras enfermedades que lo aquejaban. También tuvo que cambiar sus esquemas de medicamentos por los efectos adversos que le provocaron. Al momento de su entrevista estaba tomando dos comprimidos por día. Al hablar de la indetectabilidad siempre dijo que era algo que no entendía mucho pero que lo «ponía contento», sobre todo en lo referido a sus relaciones sexuales.

A Leandro le preocupaba mucho su aspecto físico. Con sus mejillas hundidas, sus dientes faltantes y sus brazos flacos, decía encontrarse poco deseable, poco atractivo. Muchas veces me dijo que extrañaba ser mirado por las mujeres en la calle, como sucedía «antes». La relación con Martina, su esposa, casi diez años menor, era también una preocupación que Leandro trajo con frecuencia a nuestras conversaciones. Su queja recurrente por la poca frecuencia con que mantenían relaciones sexuales se enlazaba con su preocupación por su apariencia. Durante la entrevista, me dijo al respecto:

[En las relaciones sexuales] hay veces que no nos cuidamos de un principio y yo entiendo que ya no la contagio, pero [...] después me siento mal porque digo, o me estoy descuidando yo o la estoy descuidando a ella, o sea, sé que no la voy a contagiar pero... no sé, es como que a veces me molesta, es como que es todo muy protocolar y como que a veces ni me dan ganas de tener sexo, porque me siento un bicho, es como que no puedo tocar sin... pero por el otro lado está bien que la cuide, y que me cuide yo, porque ella un resfrío me lo puede pasar vía sexual o no sé tiene algo de la mujer que me pueda lastimar a mí que estoy más sensible que ella [...] (entrevista Leandro 24/04/2017 - resaltado propio).

Leandro «entiende» que «ya no contagia» pero eso no necesariamente hace que el proceso de mantener relaciones sexuales resulte más fluido y placentero, en sus palabras, deje de ser «protocolar», por esa incertidumbre que se cuela haciéndolo sentir un «bicho» ${ }^{19}$, lo cual parece aquí remitir simultáneamente a su condición de seropositividad y a su aspecto físico. Esta apreciación sobre sí recuerda a un

19 El término «bicho» ha sido ampliamente utilizado en la jerga popular para designar al VIH/ sida. 
conjunto de estudios que han planteado cómo la experiencia de fragilidad/debilidad corporal de varones con VIH pone en crisis los núcleos identitarios centrales de la masculinidad (tales como «fuerza», «potencia», «razón», «actividad»), profundizando el sufrimiento de estas personas (Grimberg, 2002a, 2002b).

Pero las respuestas de Leandro introducen un elemento adicional: podríamos denominarlo una redirección del sentido del contagio y de su fuente, una redirección del riesgo en las relaciones sexuales. En el relato de Leandro no es él - la persona con VIH - quien amenaza la seguridad de la persona sin VIH, sino a la inversa. Es él quien se presenta en condición de mayor fragilidad (llamada por él «sensibilidad») frente al entorno y en las relaciones sexuales con Martina. Es ella quien amenaza con «pasar[le] por vía sexual» enfermedades que pueden «lastimar[lo]» por su mayor «sensibilidad» relativa.

\section{LA REDIRECCIÓN DEL SENTIDO DEL CONTAGIO Y EL RIESGO EN LA INDETECTABILIDAD}

Un movimiento similar se produce en los relatos que Rafael elabora al hablar de su indetectabilidad en el contexto de sus relaciones sexuales. Conversamos sobre ello desde la primera vez que nos vimos, cuando me dijo: «Yo soy un talibán de la medicación» y continuó señalando «cuando empecé [con el tratamiento] yo a los cuatro meses me negativicé». Así comenzó mi vínculo con este varón gay de 47 años, cuyo pelo completamente canoso (al igual que su barba) siempre estaba recortado con magistral precisión. Rafael es modisto y siempre acudía al CAP con ropa hecha por él, de colores y texturas estridentes, llamaba la atención en el espacio de la sala de espera. Conocí a su pareja «serodiscordante» (como lo presentó), con quien vivía a unas pocas cuadras del centro de salud, el día que acudí allí a entrevistarlo. Rafael había recibido su diagnóstico en 2015 y comenzó su tratamiento antirretroviral a los pocos meses. Fiel a su condición de «talibán», nunca había abandonado su tratamiento, aunque realizaba pequeños ajustes cotidianos en función de situaciones determinadas, por ejemplo, los días que saldría por la noche, retrasar o evitar la toma de su pastilla nocturna. Tomaba sus comprimidos dos veces por día. Para Rafael estar indetectable era parte de su carta de presentación, y decía: «[Cuando estás indetectable] estás liberado en realidad, porque hasta tenés ganas de decirlo, muchas veces cuando vos decís "tengo la carga viral indetectable" [...] como que te libera» (entrevista Rafael 15/03/2017 - resaltado propio). 
La posibilidad de «decir» que tiene la carga viral indetectable era para Rafael la oportunidad de compartir - con otros - que tiene VIH, pero que ya no transmite el virus, movimiento que mostraría que ya no se es peligroso para el entorno. Pero este movimiento que podría ser leído como una forma de alivio, por estar acompañado de la promesa de una vida donde la sexualidad pueda ser vivida plenamente - recordemos la promesa del TasP de poder elegir mantener relaciones sexuales sin preservativo y también sentirse liberado del estigma asociado a vivir con el virus - no se completa en las relaciones sexuales de Rafael. La indetectabilidad no restituye para él la posibilidad de tener relaciones sexuales, práctica que interrumpió cuando recibió su diagnóstico:

Hoy estoy en una situación extrema sexualmente, no tengo situaciones sexuales, acercamientos sexuales por temores miles [...] te tenés que super cuidar, no querés contagiar, no querés exponerte a contagiarte otras cosas peores, entonces eso es lo que te va cerrando, a mí me va cerrando, vas teniendo menos sexo, y con más cosas, o sea con preservativo de una cosa, que no podes tener sexo oral, que mucha gente no quiere tener sexo oral con preservativo [...] te vas cerrando, uno mismo se va cerrando cuando convivís con ese tema, te cambia la pareja [...] hoy por hoy a mí o sea en mi persona, pienso en fluidos y ya me pongo de malhumor, entonces te condiciona, es bastante traumático, hay que trabajarlo, pero los cuidados... es mucho el trabajo que tenés que hacer para tener sexo [...] entonces la gente se empieza a descuidar, se piensan que llegar al indetectable es no tener más virus, y no es, te tenés que cuidar igual porque sos propenso a cualquier cosa [...] ahora que estás en esta situación vos sos el que más se tiene que cuidar del entorno, no el entorno de vos [...] un hetero, ponele, o una persona gay que no se cuida, le puede hacer más mal a una persona que vive con VIH controlada [...] entonces me tengo que cuidar diez veces más yo que vos [...] y eso es una cosita medio extraña, ¿viste?, medio que te va condicionando a tener otro tipo de sexo, a tener otro tipo de cuidados, y entre todo ese trabajo, ¿viste?, lleva, lleva un montón de tiempo... te condiciona, y es más, si llego a tener hoy una relación sexual, creo que es hasta que ni siquiera quiero besar a esa persona, que ni siquiera quiero que me bese, por temores miles [...] (entrevista Rafael 15/03/2017 - resaltado propio).

Por un lado, el relato de Rafael muestra los modos en que se refuerza el imperativo moral históricamente vinculado con la denominada adherencia a los tratamientos en el VIH-sida (Margulies, 1998), aunque ahora asociado a la indetectabilidad, reforzando la responsabilidad moral de gestionar el propio riesgo para cuidar de sí y de otros. Por el otro, aunque «libere» frente a la carga del secreto, la indetectabilidad no permite restablecer las relaciones ni prácticas sexuales 
habituales ni permite reconstruir para Rafael una sexualidad plena. Tampoco disuade de temores que se asocian a la posibilidad de «contagiar o contagiarse cosas peores», ni evita que el sexo resulte «mucho trabajo». Como en el caso de Leandro, es Rafael quien ahora es amenazado por otros («el hetero», «el gay que no se cuida», la pareja seronegativa) que podrían «contagiar cosas peores» - peligrosas - en las relaciones sexuales. Así, la sexualidad se constituye en el locus de peligrosidad para el sujeto con VIH «controlado» porque amenaza el trabajo cotidiano de cuidados y de control de riesgos, colocando en jaque la seguridad que la misma indetectabilidad permitiría alcanzar.

\section{CONCLUSIONES}

Como ya hemos señalado, en el contexto del Tasp, la ecuación I=I se presenta simultáneamente como la clave para poner fin a la epidemia y como una poderosa herramienta para responder al estigma de las personas con VIH (The Lancet HIV, 2017; UNAIDS, 2018a; DSETSHyT, 2019). A partir de nuestro análisis hemos señalado los modos en que estas políticas reavivan algunos de los núcleos centrales en los debates históricos alrededor del VIH/sida, expresados a través de las nociones articuladas de contagio-cuidado-responsabilidad, que remiten a la inicial construcción moral de la epidemia. Aun cuando el TasP se presenta como la posibilidad de liberar a los sujetos del estigma asociado al sida, en la experiencia relatada de la vida con la enfermedad y el tratamiento de nuestros entrevistados vemos reemerger viejos imperativos morales que caracterizaron a la epidemia desde sus inicios. Asimismo, encontramos en los discursos y documentos oficiales una visión racionalista y una noción de relación lineal entre saber y hacer, expresada como que el saber que no se transmite el virus abre a los afectados a la posibilidad de elegir una vida sexual plena y liberada del estigma del VIH/sida. Sin embargo, nuestro análisis pone en cuestión este planteo intelectualista/voluntarista, ya que, lejos de encontrarnos con una relación cierta entre carga viral indetectable, eliminación de la trasmisión y vida sexual plena, hemos podido relevar la complejidad de la experiencia, y los procesos tensos, en ocasiones ambivalentes, entre percepcióninterpretación-significación y prácticas relativas al tratamiento y los cuidados de las personas con VIH.

Finalmente, las políticas y discursos que tienen como centro al TasP colocan un nuevo sentido de responsabilidad, asociado a la posibilidad de transformarse en un agente de prevención en el camino de poner fin a la epidemia a través 
del sostenimiento de la propia carga viral a niveles indetectables. (UNAIDS, 2018b). Es decir, los sujetos son colocados bajo el deber de adherir al tratamiento antirretroviral no solo para cuidar de sí (disminuir la progresión viral), sino fundamentalmente para cuidar de otros (evitar transmitir el virus) y así poner fin a la epidemia (eliminar la transmisión viral), generando novedosas cargas para las personas con VIH. Tal proceso pone también en evidencia la individualizaciónresponsabilización contenidas en los discursos globales y locales del sida y que opera en las propias interacciones clínicas. Tal individualización-responsabilización, y la presión por la racionalización (o control racional de la vida y los comportamientos) que la misma supone, coloca a los sujetos en una situación de incertidumbre y fragilidad. Nuestro análisis etnográfico muestra que en este proceso simultáneamente aparece un redireccionamiento del sentido del riesgo que implica un control ya no solamente del riesgo propio — del daño potencial que cada sujeto con VIH podría generar a otros- sino también un control del riesgo que otros presentan para las personas con VIH controladas, mostrando las dificultades a la vez somáticas y de los ajustes cotidianos que estos sujetos deben afrontar. Así, frente al discurso técnico-científico y político que - sustentado en un enfoque de elección racional - anuncia el fin del estigma en camino al fin de la epidemia, proponemos una mirada sobre cómo las personas con VIH, aun indetectables, navegan estas configuraciones políticas y tecnológicas contemporáneas del sida y los procesos de protección — pero también de fragilidad— que estas nuevas/viejas materialidades introducen en sus vidas, en particular en sus relacionamientos sexuales.

\section{REFERENCIAS}

Alonzo, Angelo A. y Nancy R. Reynolds (1995). Stigma, HIV and AIDS: An exploration and elaboration of a stigma trajectory. Social Science and Medicine, 41(3), 303-315. https://doi.org/10.1016/0277-9536(94)00384-6

Alves, Paulo César (2014). Narrativas de itinerários terapêuticos e doenças crônicas. En 29a Reunião Brasileira de Antropologia (pp. 1-14). Natal, RN. Recuperado de http://www.29rba.abant.org.br/resources/anais/1/1401992219_ARQUIVO_ SOBREITINERARIOTERAPEUTICO.pdf

Aronowitz, Robert (2015). Risky Medicine: our quest to cure fear and uncertainty. Chicago, IL: The University of Chicago Press. https://doi.org/10.7208/ chicago/9780226049854.001.0001 
Bauman, Richard y Charles L. Briggs (1990). Poetics and Performance as Critical Perspectives on Language and Social Life. Annual Review of Anthropology, 19, 59-88. https://doi.org/10.1146/annurev.an.19.100190.000423

Biehl, João G. (2007). Will to Live: AIDS therapies and the politics of survival. Princeton, NJ: Princeton University Press.

Biehl, João G. (2008a). Drugs for All: The Future of Global AIDS Treatment. Medical Anthropology, 27(2), 99-105. https://doi.org/10.1080/01459740802022777

Biehl, João G. (2008b). Pharmaceuticalization: AIDS treatment and Global Health Politics. Anthropology Quarterly, 80(4), 1083-1126. https://doi.org/10.1353/ anq.2007.0056

Biehl, João G. y Amy Moran-Thomas (2009). Symptom: Subjectivities, Social Ills, Technologies. Annual Review of Anthropology, 38(1), 267-288. https://doi. org/10.1146/annurev-anthro-091908-164420

Carrithers, Michael, Matei Candea, Karen Sykes, Martin Holbraad y Soumhya Venkatesan (2010). Ontology is just another word for culture: Motion tabled at the 2008 meeting of the group for debates in anthropological theory, University of Manchester. Critique of Anthropology, 30(2), 152-200. https://doi. org/10.1177/0308275X09364070

Castro, Arachu y Paul Farmer (2003). El sida y la violencia estructural: la culpabilización de la víctima. Cuadernos de Antropología Social, 2003(17), 29-47.

Cormier McSwiggin, Chelsea (2017). Moral Adherence: HIV Treatment, Undetectability, and Stigmatized Viral Loads among Haitians in South Florida. Medical Anthropology: Cross Cultural Studies in Health and Illness, 36(8), 714-728. https://doi.org/10.1080/01459740.2017.1361946

Crawford, Anne M. (1996). Stigma associated with AIDS: A meta-analysis. Journal of Applied Social Psychology, 26(5), 398-416. https://doi. org/10.1111/j.1559-1816.1996.tb01856.x

DSETSHyT (2013). Guía para el manejo de los pacientes adultos con infección por VIH. Buenos Aires: Ministerio de Salud de la Nación.

DSETSHyT (2018). Guía práctica para la atención integral de personas con VIH en el primer nivel de atención. Buenos Aires: Ministerio de Salud de la Nación.

DSETSHyT (2019). I=I / Indetectable=Intransmisible: Ausencia de transmisión sexual del VIH en personas bajo tratamiento antirretroviral y con carga viral indetectable. Documento de consenso de la Dirección de Sida, ETS, Hepatitis y TBC. Buenos Aires: Ministerio de Salud de la Nación. 
Ecks, S. (2005). Pharmaceutical citizenship: Antidepressant marketing and the promise of demarginalization in India. Anthropology and Medicine, 12(3), 239-254. https://doi.org/10.1080/13648470500291360

Fassin, D. (2007). When Bodies Remember: experiences and politics of AIDS in South Africa. Berkeley y Los Angeles, CA: University of California Press.

Frankenberg, R. (1986). Sickness as cultural performance: drama, trajectory, and pilgrimage root metaphors and the making social of disease. International Journal of Health Services, 16(4), 603-626. https://doi.org/10.2190/TH4R-BJR9-WGF6HEBM

Frankenberg, R. (1994). The impact of HIV/AIDS on concepts relating to risk and culture within British community epidemiology: Candidates or targets for prevention. Social Science and Medicine, 38(10), 1325-1335. https://doi.org/10.1016/02779536(94)90271-2

García, M. G. (2014). Maternidad y VIH-sida. Un estudio antropológico del proceso de atención del embarazo, parto y puerperio de mujeres que viven con el virus. Buenos Aires: Universidad de Buenos Aires.

González-Abrisketa, O. y S. Carro-Ripalda (2016). La apertura ontológica de la antropología contemporánea. Revista de Dialectología y Tradiciones Populares, 71(1), 101-128. https://doi.org/10.3989/rdtp.2016.01.003

Good, B. J. (1993). Medicine, Rationality and Experience: An Anthropological Perspective. Lewis Henry Morgan Lectures. Nueva York, NY: Cambridge University Press. https://doi.org/10.1017/CBO9780511811029

Grimberg, Mabel (2002a). Iniciación sexual, prácticas sexuales y prevención al VIH/ sida en jóvenes de sectores populares: un análisis antropológico de género. Horizontes Antropológicos, 8(17), 47-75. https://doi.org/10.1590/S010471832002000100003

Grimberg, Mabel (2002b). VIH-sida, vida cotidiana y experiencia subjetiva. Una revisión conceptual de las dimensiones de vivir con VIH. Cuadernos Médico Sociales, 82, 43-59.

Holbraad, M. (2014). Tres provocaciones ontológicas. Ankulegi: Gizarte Antropologia Aldizkaria = Revista de Antropología Social, (18), 127-139.

IAS (2011). Conference Summary report on the 6 th IAS Conference on HIV pathogenesis, treatment and prevention (IAS 2011): Research highlights and Implications for policy and practise. Roma, 17-20 de julio de 2011.

Lloyd, K. C. (2018). Centering «being undetectable» as the new face of HIV: Transforming subjectivities via the discursive practices of HIV treatment as prevention. BioSocieties, 13(2), 470-493. https://doi.org/10.1057/s41292-017-0080-1 
Manderson, L. y C. Smith-Morris (2010). Chronic Conditions, Fluid States (January), 20-37.

Margulies, Susana (1998). Candidaturas y VIH-sida: tensiones en los procesos de atención. Cuadernos Médico Sociales, 063, 1-10.

Margulies, Susana (2015). Ponencia - Simposio 19. En XI Reunión de Antropología del Mercosur. Montevideo.

Merkier, H. y Susana Margulies (1998). Atención de pacientes con VIH-sida y personal de enfermería: la construcción social de la bioseguridad. En Actas del V Congreso de Antropología Social.

Mol, Annemarie (2002). The Body Multiple: Ontology in Medical Practice. Durham, NC: Duke University Press.

Mol, Annemarie y John Law (2004). Embodied Action, Enacted Bodies Hypoglycaemia. Body \& Society, 10(3), 43-62. https://doi.org/10.1177/1357034X04042932

Montaner, J. S. (2011). Treatment as prevention - a double hat-trick. The Lancet, 378, 16-17. https://doi.org/10.1016/S0140-6736(11)60821-0

Montaner, J. S., R. Hogg, E. Wood, T. Kerr, M. Tyndall, A. R. Levy y P. R. Harrigan (2006). The case for expanding access to highly active antiretroviral therapy to curb the growth of the HIV epidemic. The Lancet, 368(9534), 531-536. https:// doi.org/10.1016/S0140-6736(06)69162-9

Moyer, E. (2015). The Anthropology of Life After AIDS: Epistemological Continuities in the Age of Antiretroviral Treatment. Annual Review of Anthropology, 44(1), 259-275. https://doi.org/10.1146/annurev-anthro-102214-014235

Nguyen, V. (2004). Antiretroviral globalism, biopolitics and therapeutic citizenship. En A. Ong y S. Collier (eds.), Global Assemblages: Technology, Politics, and Ethics as Anthropological Problems (pp. 124-144). https://doi. org/10.1002/9780470696569.ch8

Novas, C. y N. Rose (2000). Genetic risk and the birth of the somatic individual. Economy and Society, 29(4), 485-513. https://doi.org/10.1080/03085140050174750

Oxman, C. (1998). La entrevista de investigación en ciencias sociales. Buenos Aires: Eudeba.

Persson, A., A. Kelly-Hanku, S. Bell, A. Mek, H. Worth y R. Nake Trumb (2019). «Vibrant Entanglements»: HIV Biomedicine and Serodiscordant Couples in Papua New Guinea. Medical Anthropology: Cross Cultural Studies in Health and Illness, 38(3), 267-281. https://doi.org/10.1080/01459740.2018.1530670

Persson, A., K. Race y E. Wakeford (2003). HIV health in context: Negotiating medical technology and lived experience. Health: An Interdisciplinary Journal for 
the Social Study of Health, Illness and Medicine, 7(4), 397-415. https://doi. org/10.1177/13634593030074002

Petryna, Adriana (2004). Biological citizenship: the science and politics of Chernobylexposed populations. Osiris, 19, 250-265. https://doi.org/10.1086/649405

Petryna, Adriana, Andrew Lakoff y Arthur Kleinman (2006). Global Pharmaceuticals: Ethics, Markets, Practices. Durham: Duke University Press. https://doi. org/10.1215/9780822387916

Pierret, J. (2000). Vivir con el VIH en un contexto de enfermedad crónica: aspectos metodológicos y conceptuales. Cuadernos Médico Sociales, (77), 35-44.

Poder Legislativo de la Nación Argentina. Ley Nacional de SIDA 23.798 y su decreto reglamentario 1244/91 (1990).

Rabinow, P. (2008). Artificiality and Enlightenment: From Sociobiology to Biosociality. En Jonathan Xavier Inda (ed.), Anthropologies of Modernity: Foucault, Governmentality, and Life Politics (pp. 179-193). Hoboken, NJ: Wiley \& Sons. https:// doi.org/10.1002/9780470775875.ch7

Reynolds Whyte, S. (2013). The Pharmaceutical Nexus. En A. Petryna, A. Lakoff y A. Kleinman Global Pharmaceuticals: Ethics, Markets, Practices. Durham, NC: Duke University Press.

Rohden, F. (2018). «Os hormônios te salvam de tudo»: produção de subjetividades e transformações corporais com o uso de recursos biomédicos. Mana, 24(1), 199-229. https://doi.org/10.1590/1678-49442018v24n1p199

Rose, N. (2001). The politics of life itself. Theory, Culture and Society, 18(6), 1-30. https://doi.org/10.1177/02632760122052020

Rose, N. y C. Novas (2008). Biological Citizenship. En Aihwa Ong y Stephen J. Collier, Global Assemblages: Technology, Politics, and Ethics as Anthropological Problems (pp. 439-463). Malden, MA: Blackwell Publishing. https://doi. org/10.1002/9780470696569.ch23

Sangaramoorthy, T. (2012). Treating the Numbers: HIV/AIDS Surveillance, Subjectivity, and Risk. Medical Anthropology: Cross Cultural Studies in Health and Illness, 31(4), 292-309. https://doi.org/10.1080/01459740.2011.622322

Sullivan, N. (2012). Enacting Spaces of Inequality: Placing Global / State Governance Within a Tanzanian Hospital. Space and Culture, 15(1), 57-67. https://doi. org/10.1177/1206331211426057

Souza, Iara Maria de Almeida (2012). A noção de ontologia múltipla e suas consequências políticas. En $36^{\circ}$ Encontro Anual da Anpocs. Recuperado de http://portal. anpocs.org/index.php/papers-36-encontro/gt-2/gt24-2/8114-a-nocao-de-ontologia-multipla-e-suas-consequencias-politicas/file 
The Lancet HIV (2017). U=U taking off in 2017. The Lancet HIV, 4(11). https://doi. org/10.1016/S2352-3018(17)30183-2

UNAIDS (2016). Acción acelerada para acabar con el sida.

UNAIDS (2018a). Undetectable = Untransmittable: Public Health and HIV Viral Load Suppression. Unaids. Recuperado de http:/www.unaids.org/sites/default/files/ media_asset/undetectable-untransmittable_en.pdf

UNAIDS (2018b). Who we are: poner fin a la epidemia de sida para el 2030. Recuperado de http://www.unaids.org/es/whoweare/about

Vernazza, P., B. Hirschel, E. Bernasconi y M. Flepp (2008). HIV-positive individuals without additional sexually transmitted diseases (STD) and on effective anti-retroviral therapy are sexually non-infectious. Bulletin des médecins suisses, 89(5), 165-169. 